\title{
Diálogo entre as terapias centrada no cliente e do esquema
}

\author{
Dialogue between the client-centered and schema therapies
}

\author{
Marcel Gomes Oliveira \\ Universidade Federal da Bahia \\ Paulo Coelho Castelo Branco \\ Universidade Federal do Ceará \\ Brasil
}

\begin{abstract}
Resumo
Objetivamos introduzir um diálogo teórico e comparativo entre a terapia centrada no cliente, de Carl Rogers, e a terapia do esquema, de Jeffrey Young. Inicialmente, apresentamos o planejamento metodológico bibliográfico para realizar esse diálogo. Posteriormente, descrevemos seus principais conceitos e operacionalizações clínicas. Em seguida, estabelecemos aproximações e distanciamentos. Os pontos de interlocução encontrados foram: o uso/não uso do diagnóstico no tratamento da personalidade; atenção aos processos do terapeuta como influentes na dinâmica terapêutica; a questão da sustentação empática em termos de compreensão e confrontação; a diretividade e não diretividade na postura terapêutica; semelhança entre os conceitos de campo fenomenológico e esquema; as noções de self; os modos de autodefesa; a importância dos afetos e emoções nas intervenções clínicas; as formas de alcançar uma ressignificação terapêutica. Concluímos com a observação de que a terapia centrada no cliente deixou um legado que serviu de referência para algumas abordagens psicoterapêuticas cognitivas e comportamentais.
\end{abstract}

Palavras-chave: terapia centrada no cliente; terapia cognitiva; terapia cognitiva-comportamental; psicologia clínica; psicologia humanista.

\begin{abstract}
We aim to introduce a theoretical and comparative dialogue between Carl Rogers' client-centered therapy and Jeffrey Young's schema therapy. Initially, we present the bibliographic methodological planning to achieve this dialogue. Later, we describe its main concepts and clinical operations. Next, we establish approximations and distances. The interlocution points found were: the use/non-use of diagnosis in the personality treatment; attention to the therapist's processes as influential in dynamic therapeutic; the question of empathic support in terms of understanding and confrontation; the directivity and non-directivity in therapeutic posture; similarity among the phenomenological field and schema concepts; the notions of self; the selfdefense modes; the importance of affections and emotions in clinical interventions; ways to achieve a therapeutic re-signification. We conclude with the observation that client-centered therapy left a legacy that served as a reference for some cognitive and behavioral psychotherapeutic approaches.
\end{abstract}


Keywords: client-centered therapy; cognitive therapy; cognitive behavioral therapy; clinical psychology; humanistic psychology.

\section{Introdução}

Carl Rogers deixou um legado concernente a uma proposta terapêutica individual e grupal que, posteriormente, influenciou diversas outras perspectivas clínicas e educacionais. Nesse sentido, o psicólogo humanista foi aberto ao diálogo com variadas vertentes teóricas e pensadores, a exemplo do que Kirschenbaum e Henderson (1990) compilaram das conversas de Rogers com Rollo May, Martin Buber, Paul Tillich, Burrhus Skinner, Michael Polanyi e Gregory Bateson. Além disso, mencionam-se as leituras internas e releituras externas de outras abordagens (psicanalítica, transpessoal, gestáltica, feminista e cognitivacomportamental) dos principais casos clínicos de Rogers, organizados por Farber, Brink e Raskin (2001).

Diante desse legado muitos pós-rogerianos também desenvolveram interlocuções do pensamento de Rogers com a Psicanálise (Gusmão, 2011), Psicologia Comportamental (Milhollan \& Forisha, 1972/1978; Nye, 1981/2005), Psicologia Positiva (Paludo \& Koller, 2007; Scorsolini-Comin, 2014), Psicologia Transpessoal (Boainain, 1998), Gestalt-Terapia (Moreira, 2010), Fenomenologia (Moreira, 2007; Castelo Branco \& Cirino, 2016a), Pragmatismo (Castelo Branco \& Cirino, 2016b), Existencialismo (Holanda, 1998; Ponte, 2010; Pinheiro \& Vieira, 2011), Pedagogia freiriana (Castelo Branco, Monteiro \& Felix, 2016), Teoria Sistêmica do Caos (Gobbi, 2002) e Arqueologia foucaultiana (Campos, 2017), apenas para citar alguns.

A despeito disso, diálogos teóricos entre a teoria rogeriana e a Psicologia Cognitiva-Comportamental, sobretudo a terapia do esquema, são inexistentes. Ressalta-se que a terapia do esquema possui inspirações humanistas (Falcone \& Ventura, 2008), ao passo que há menções de influências do trabalho de Rogers no que concerne ao estabelecimento de uma relação terapêutica flexível, acolhedora, genuína e empática, em que o terapeuta considera as idiossincrasias da personalidade do cliente. Não obstante, a terapia do esquema parte desses princípios e busca ir além deles para oferecer outras possibilidades terapêuticas ao cliente ante as suas necessidades não atendidas e desadaptações (Rafaeli, Bernstein \& Young, 2011).

Em função disso que entendemos que o trabalho rogeriano que foi influente para a terapia do esquema concerniu à terapia centrada no cliente, uma proposta clínica que visa à reorganização e mudança de personalidade, cuja eficácia foi 
comprovada nos anos em que Rogers trabalhou na Universidade de Chicago (Rogers, 1959/1977). Logo, diante da diversidade dos trabalhos de Rogers nos âmbitos do aconselhamento psicológico, da psicoterapia e das intervenções educacionais e grupais, restringimos a operacionalização de sua abordagem quanto à esfera da terapia centrada no cliente, sobretudo referentes aos trabalhos desenvolvidos nos anos de 1950, os quais contêm a base teórica de sua proposta clínica.

Destarte, este estudo objetiva introduzir um diálogo teórico e comparativo entre a terapia centrada no cliente, de Carl Rogers, e a terapia do esquema, de Jeffrey Young. Para isso, inicialmente, organizamos um plano metodológico para organizar esse diálogo. Em seguida, apresentamos sucintamente os elementos que embasam tais terapias, em seus principais conceitos e operacionalizações clínicas. Finalmente, estabelecemos algumas aproximações e distanciamentos entre elas.

\section{Método}

Antes de prosseguir, ressalta-se que tomamos a noção de diálogo como um exercício intelectual de alternância entre interlocutores com origens e visões distintas, mas capazes de criar transações de ideias que geram novos entendimentos sobre um fenômeno em comum (Crapanzano, 1991), neste caso a terapia.

Com efeito, procedemos de um desenho de pesquisa bibliográfica inspirado pelos aportes de Lima e Mioto (2007) em que selecionamos obras concernentes aos campos das terapias centrada no cliente e do esquema conforme as suas intervenções relacionadas à personalidade. O motivo desse recorte remete ao argumento de que esse objeto de estudo e intervenção foi o elemento e fio condutor que possibilitou tal diálogo, dado que a terapia do esquema reconhece os trabalhos clínicos rogerianos sobre o self como influentes (Falcone \& Ventura, 2008; Rafaeli e outros, 2011). Merece menção que a falta da ênfase de Rogers em relação à psicoterapia e mudança de personalidade, após sua aposentadoria nos anos de 1960, decorre de que os seus trabalhos educacionais e grupais não objetivavam isso e, também, enfatizavam um contato mais direto com a experiência em seu fluxo corrente. Logo, esse legado não foi concernido pela terapia do esquema.

A partir das técnicas de leitura de reconhecimento do material bibliográfico e leitura exploratória (Lima \& Mioto, 2007), compilamos as seguintes obras rogerianas: Terapia Centrada no Cliente (Rogers, 1951/1992), Psicoterapia e 
Relações Humanas: teoria e prática da terapia não-diretiva, Volume 1 (Rogers, 1959/1977) e Volume 2 (Rogers \& Kinget, 1962/1977), As condições necessárias e suficientes para mudança terapêutica na personalidade (Rogers, 1957/2008). Além disso, reunimos as seguintes obras youngianas: Terapia cognitiva para transtornos da personalidade: uma abordagem focada em esquemas (Young, 1999/2003), Terapia do esquema: guia de técnicas cognitivo-comportamentais inovadoras (Young, Klosko \& Weishaar, 2003/2008) e Schema therapy: distinctive features (Rafaeli e outros, 2011) e a entrevista de Young concedida a Falcone e Ventura (2008). Conquanto existam outras obras que possam versar os autores em diálogo, restringimo-nos a esses textos por considerá-los representativos para cumprir o objetivo.

Em posse desse material, procedemos de uma técnica de leitura seletiva aos elementos teóricos relacionados aos procedimentos clínicos das terapias em tela. Esse material foi organizado em uma leitura reflexiva e sintética sobre as suas proposições interventivas. Por fim, empregamos uma leitura interpretativa em que relacionamos algumas ideias das terapias centrada no cliente e do esquema de modo a estabelecer um diálogo entre elas (Lima \& Mioto, 2007).

\section{Terapia centrada no cliente de Carl Rogers}

Em linhas gerais, a terapia centrada no cliente consistiu em uma primeira teoria e prática de trabalho clínico exercido por psicólogos, e não médicos de formação psicanalítica, que objetiva uma mudança de personalidade. A partir de um delineamento de pesquisa quase-experimental houve diversos estudos sobre a eficiência e os efeitos de suas intervenções sobre a personalidade em indivíduos com tensões que afetam suas autorregulações no ambiente. Tais estudos serviram para edificar um sistema terapêutico teórico e prático (Rogers, 1959/1977; Rogers \& Kinget, 1962/1977).

Para entender a estruturação da personalidade, Rogers (1951/1992) parte das relações funcionais entre organismo e ambiente. Assim, entende organismo como um sistema total, uma Gestalt, que funciona no indivíduo como o locus de todas as suas experiências, simbolizações da consciência, emoções, sentimentos, pensamentos, personalidade e percepções. O organismo sempre interage com o ambiente e reage a ele a partir do que percebe e sente, de modo a realizar os impulsos básicos de preservação e crescimento.

Rogers (1959/1977) entende experiência como tudo aquilo que se passa no organismo a todo o momento, estando potencialmente disponível à consciência. Esta é uma função epistêmica do organismo para se voltar e simbolizar o que ele 
sente. Do conjunto de impressões que foram simbolizadas ante o que foi experienciado, o campo fenomenológico emerge como um conjunto de percepções e significações sobre si, o outro e o mundo (ambiente), ocasionando a constituição de um mundo particular que irá afetar a forma como o organismo experimenta o ambiente, conscientemente ou não (Rogers, 1951/1992). Dessa forma, a realidade não é alheia ao indivíduo, mas sim guiada pela sua própria percepção e "o comportamento é, basicamente, a tentativa dirigida para uma meta que o organismo utiliza para satisfazer as necessidades que ele experimenta, no campo que ele percebe" (Rogers, 1951/1992, p. 558, grifo nosso). Nesse sentido, o comportamento se trata de uma reação ao campo fenomenológico e uma expressão da experiência no ambiente. Tais expressões que direcionam o organismo para a realização de uma meta parecem ser transmitidas por uma força via processos orgânicos e intelectuais. Assim, "todo organismo é movido por uma tendência inerente para desenvolver todas as suas potencialidades e para desenvolvê-las de maneira a favorecer sua conservação e seu enriquecimento" (Rogers, 1959/1977, p. 159). Esta tendência é nomeada como autorrealização.

As emoções, os sentimentos e as atitudes, também, fazem parte do esforço de realizar metas, e sua variação de intensidade depende da relação percebida do comportamento com a preservação e grau de envolvimento do self nesse movimento. Rogers (1951/1992) define self como uma função organísmica resultante da interação entre as demandas internas do organismo e as demandas externas encontradas no ambiente (como outras experiências, juízos, sociedade e cultura). Em conjunto com a avaliação do outro, a estrutura de self é formada como "um padrão conceitual organizado, fluido e coerente de percepções de características e relações do 'eu' ou do 'mim', juntamente com valores ligados a esses conceitos" (Rogers, 1951/1992, p. 566). O reconhecimento do campo fenomenológico aqui parece estar presente desde o desenvolvimento precoce do indivíduo, ainda quando bebê, na forma de construção de percepções e conceitos de si mesmo.

Ao refletir acerca da estrutura do self, Rogers (1951/1992) afirma que esse autoconceito pode ser direcionado tanto em relação aos outros como ao ambiente. Assim, as experiências podem: ser simbolizadas, percebidas e organizadas em relação ao self; ignoradas, pois não há relação percebida com sua estrutura; ou ter a sua simbolização negada/distorcida. O processo de satisfação do self ocorre no deslocamento do plano perceptual de fundo para a figura. Por vezes, porém, as experiências são negadas à consciência ainda que o indivíduo não esteja ciente desse processo. Este fenômeno é denominado 
subcepção e faz com que as simbolizações de experiências que são ameaçadoras para o self sejam deformadas (Rogers, 1959/1977), ou seja, distorcidas.

Torna-se, portanto, mais evidente os processos envolvidos na mudança da personalidade, uma vez que o aspecto da intencionalidade organísmica estará sempre presente, pois o organismo apresenta funções autorrealizadoras com objetivo de diminuição das tensões em uma inter-relação entre suas demandas internas e externas. Isto fica claro na teoria de Rogers (1951/1992) quando é tratada a noção de desajustamento e ajustamento psicológico. O desajuste ocorre durante situações em que a pessoa nega à sua consciência, experiências significativas que não foram de alguma forma simbolizadas pelo seu self, gerando uma tensão. Ao contrário disso, a noção de ajustamento advém do fato de que as experiências são simbolizadas e assimiladas coerentemente ao self, fortalecendo e facilitando o movimento rumo ao crescimento.

Em relação à operacionalização da relação terapêutica, Rogers (1959/1977), postula que: "Se são dadas certas condições (variáveis independentes), então um processo determinado (variáveis dependentes) produzirá (...) certas modificações da personalidade e do comportamento (variáveis dependentes) " (p. 182). Desta forma, o autor está preocupado em estabelecer as regularidades e as pressuposições da mudança da personalidade na clínica. Esta concepção se define não apenas como uma mudança em nível superficial, mas também igualmente profunda da personalidade em direção integrativa com menor grau de conflito interno. Assim, unido à mudança de comportamento, afastam-se expressões consideradas imaturas em troca daquelas amadurecidas. Seguem-se as seis condições para que a personalidade se reorganize no processo terapêutico (Rogers, 1957/2008, 1959/1977).

(1) Que duas pessoas, o psicoterapeuta e o cliente, estejam em contato. Espera-se que exista uma condição mínima de relação entre os dois, em que haverá a percepção ou sentimento de presença mútua. Portanto, esta primeira condição é, na realidade, uma pré-condição, visto que sem ela as seguintes não se sucederão satisfatoriamente.

(2) Que o cliente esteja em um estado de incongruência, apresentando-se vulnerável ou ansioso. Incongruência é um construto teórico referente a um desacordo interno entre três dimensões: a experiência real do organismo, o processo de simbolização do self pela consciência e sua expressão no comportamento. Ou seja, há uma tensão entre o que o cliente sente (pela experiência), pensa (simboliza pela consciência) e faz (pelo comportamento). 0 estado de vulnerabilidade ocorre quando o cliente não está consciente de sua 
incongruência, enquanto a ansiedade acontece quando há uma percepção vaga do que causa sua tensão.

(3) Que o psicoterapeuta esteja em um estado de congruência, nos limites da relação. Espera-se, pois, uma postura de autenticidade em que, no momento do encontro clínico, o psicólogo atente para o que se passa em sua experiência, consciência e comportamento. A experiência real do contato se torna, então, precisamente representada no seu self do psicoterapeuta, tornando uma possível incongruência consciente e sustentável na relação.

(4) Que o psicoterapeuta experiencie consideração positiva incondicional pelo cliente. Ou seja, que o psicólogo considere a experiência alheia como um lugar de conhecimento válido evitando impor julgamentos de valores, deixando isso para o próprio cliente elaborar a partir de sua percepção.

(5) Que o psicoterapeuta experiencie uma compreensão empática do esquema de referência interno do cliente e se esforce para comunicar-lhe esta experiência. Sobre o conceito de empatia, Rogers (1957/2008) o indica como o cuidado de sentir o mundo experiencial do cliente, como se fosse o seu, porém sem perder de vista a qualidade do "como se". O terapeuta, ao adentrar este quadro de referência, tem a possibilidade de acessar os conteúdos e significados do que se passa com o cliente em sua percepção.

(6) Que a comunicação ao cliente da compreensão empática e da consideração positiva incondicional seja efetivada, pelo menos, em um grau mínimo. Isto implica uma comunicação verbal e subverbal (expressões fisionômicas, por exemplo).

Rogers e Kinget (1962/1977) apresentam, ainda, uma série de respostas clínicas possíveis de serem usadas por terapeutas frente a uma demanda apresentada pelo cliente. Tais respostas são divididas em cinco categorias, seguidas de suas finalidades clínicas: (1) estimativa, caracterizada por expressar certa opinião relativa ao mérito-demérito, à utilidade, à exatidão, ao fundamento do que o cliente disse - ou seja, indica, de algum modo, como o cliente poderia ou deveria agir; (2) interpretativa, visa de algum modo instruir o cliente a seu próprio respeito, fazendo-o tomar consciência de algo - de forma direta ou indireta, indica como o cliente poderia ou deveria representar para si seu problema; (3) tranquilizadora, pretende aliviar a tensão, apaziguando-a pela pressuposição de que há outra visão do problema, ou que ele não existe; (4) exploradora, intenciona verificar e/ou aprofundar algo da discussão, sugerindo que o cliente poderia ou deveria examinar melhor o problema; (5) compreensiva, objetiva apreender o referencial interno do cliente, preocupando-se com o sentido-significado do que ele sente, pensa e faz. 
Diante desse quadro de respostas em relação à demanda expressa pelo cliente, Rogers e Kinget (1962/1977) demarcam que as respostas compreensivas são as mais representativas e adequadas à proposta centrada no cliente; e que os outros tipos de respostas podem ser entendidos como parâmetros de como não proceder predominantemente nessa perspectiva. Assim, o terapeuta deve estar consciente se ele estiver interpretando, explorando, tranquilizando ou estimando o cliente, entendendo qual é a necessidade clínica dessas intervenções e que a sua teleologia deve ser compreensiva.

Com base nisso, Rogers e Kinget (1962/1977) assinalam que as intervenções devem se basear na compreensão como uma apreensão do referencial interno do cliente. Assim, nomeiam como reflexo a resposta mais característica da terapia centrada no cliente. Refletir a experiência do cliente implica em sintetizar e acentuar o sentido (explícito ou implícito) do que o cliente quis comunicar. Há, pois, três diferentes modalidades de respostas reflexas: (1) a reiteração, que resume a comunicação, assinalando um elemento relevante ou reproduzindo as últimas palavras do cliente; (2) o reflexo do sentimento, que objetiva a descoberta das intenções e sentimentos inerentes às palavras; (3) a elucidação, que tenta tornar evidente outros elementos da comunicação e contexto. Partindo de diferentes finalidades clínicas, essas respostas são manifestações compreensivas que têm o papel de avançar o processo terapêutico sempre na direção que faça sentido para o cliente, enquanto que as respostas estimativas, tranquilizadoras, exploratórias e interpretativas exercem funções terapêuticas mais secundárias. Portanto, a sucessão dessas condições e respostas conduz o processo terapêutico rumo a uma mudança da personalidade.

\section{Terapia do esquema de Jeffrey Young}

A terapia do esquema faz parte da $2^{a}$ geração de terapias cognitivas que surgiram, na década de 1990, com a obra de Jeffrey Young (1999/2003), Terapia cognitiva para transtornos da personalidade: uma abordagem focada em esquemas, uma reformulação da terapia cognitiva-comportamental tradicional de Aaron Beck, desenvolvida para o tratamento de transtornos de personalidade, nos anos de 1970 (Falcone \& Ventura, 2008).

Em suma, Young (1999/2003) sintetiza em três características principais que os pacientes com transtornos de personalidade apresentam: a rigidez; a evitação; e as dificuldades interpessoais de longo prazo (crônicas). Por rigidez, o autor se baseia no DSM-IV e em sua própria experiência clínica, para apontar a presença de padrões invasivos, inflexíveis e muito duradouros como constituintes 
de diversos transtornos de personalidade. A evitação está ligada ao resultado de condicionamentos aversivos (por exemplo, a ansiedade e a depressão) relacionados às lembranças e associações. As dificuldades interpessoais, frequentemente, implicam em disfuncionalidades de acesso à realidade, como, por exemplo, os transtornos histriônicos, esquizoides, paranoides e borderline.

Os esquemas são, portanto, o modo como a pessoa organiza a sua realidade, interpreta os seus estímulos e reage a ela pela sua percepção e comportamento. Os esquemas adaptativos ao mundo são entendidos em termos de personalidade e os desadaptativos são concebidos como transtornos de personalidade (Young, 1999/2003). A terapia do esquema, destarte, trouxe contribuições à terapia cognitiva-comportamental no campo da personalidade e do desenvolvimento humano de forma indireta, pois suas premissas não tinham como objetivo construir uma teoria geral para essas áreas (Falcone \& Ventura, 2008). Assim, Young organizou um novo conjunto de técnicas e conceitos para lidar com o manejo de pacientes com esses transtornos, considerando as características mencionadas. Tais contribuições foram alcançadas através de estudos sobre a estruturação da personalidade e a existência de processos inconscientes que atuam no processo de construção da identidade. A estruturação da personalidade é compreendida como um processo natural, portanto, de bases geneticamente herdadas, característica que define o temperamento e suas tendências cognitivas, comportamentais, afetivas e motivacionais (Young e outros, 2003/2008).

Dado um amplo universo de possibilidades na formação das identidades pessoais, as quais são construídas por bases genéticas e uma complexa comunicação entre ambiente e temperamento, a terapia do esquema propõe formular a ideia de necessidades emocionais básicas. A partir de como um temperamento é expresso em um ambiente, o indivíduo busca por demonstrações afetivas dos outros, sobretudo dos seus cuidadores no início de sua vida. Essa necessidade pode variar de acordo com a fase de desenvolvimento humano, ao passo que na idade adulta, por exemplo, pode haver um maior limite afetivo (Rafaeli e outros, 2011). Assim, o temperamento determina a quantidade ideal de necessidades emocionais básicas requeridas pelo sujeito. A terapia do esquema considera o papel dos cuidadores ao disponibilizar, em diferentes graus e etapas do desenvolvimento, as necessidades básicas das crianças ao longo dos seus primeiros anos ou na adolescência. Outros estímulos ambientais são igualmente relevantes, como as experiências continuadas, vivências traumáticas e/ou positivas. 
Sobre as emoções e as memórias traumáticas da infância, Young (1999/2003) utiliza os estudos sobre a rede cerebral associada ao condicionamento do medo e trauma. No psiquismo existem dois sistemas distintos de processamento da informação que são consciente e inconsciente e operam em paralelo. O primeiro sistema é mediado pelo hipocampo e pelas áreas corticais; o segundo, pela amígdala. Young (1999/2003) se baseia nessas diferenças locais de armazenamento das memórias para explicar a razão de alguns comportamentos não serem modificados por métodos cognitivos simples. Portanto, a terapia do esquema irá alcançar mudanças terapêuticas efetivas quando houver ressignificações que permitam ao indivíduo a modificação dos estilos de enfrentamento de esquemas considerados disfuncionais.

Considerando-se as mencionadas características dos pacientes com transtornos de personalidade, Young (1999/2003) propôs uma clínica composta por cinco constructos teóricos principais: esquemas iniciais desadaptativos (EIDs); domínios esquemáticos (DEs); manutenção de um esquema; evitação de um esquema; e compensação de um esquema.

Young (1999/2003) define os EIDs como: "temas extremamente estáveis e duradouros que se desenvolvem durante a infância, são elaborados ao longo da vida e são disfuncionais em algum grau significativo" (p. 15). Além de serem gerados através do temperamento, também sofrem influência de experiências sistemáticas com figuras de afeto na infância, bem como o grau em que o indivíduo recebeu de necessidades emocionais básicas durante cada período do seu desenvolvimento.

Os EIDs são agrupados em cinco categorias de DEs, referentes a cinco etapas evolutivas do desenvolvimento da personalidade (Young e outros, 2003/2008). Pelo fato da teoria do esquema ser estudada à luz de um caráter clínico, as nomenclaturas utilizadas já indicam situações de necessidades emocionais não totalmente satisfeitas. Logo, Young e outros (2003/2008) dividem os seguintes DEs. (1) Desconexão e rejeição: indivíduos com EIDs desse domínio, frequentemente, acreditam que suas necessidades básicas de cuidado, proteção, empatia, segurança e estabilidade não serão atendidas. (2) Autonomia e desempenho prejudicados: dificuldades em perceber sua capacidade de viver de forma independente e funcional. (3) Limites prejudicados: dificuldade em respeitar os direitos de outras pessoas e em cumprir metas e compromissos pessoalmente assumidos. (4) Orientação para o outro: preocupação exacerbada com as necessidades alheias em detrimento das próprias. (5) Supervigilância e inibição: esforço em demasia para cumprir regras rígidas e inflexíveis quanto ao desempenho pessoal. 
Independente do impacto dos cuidadores no desenvolvimento humano, as pessoas irão desenvolver estratégias próprias para poderem lidar com seus esquemas, impedindo uma contínua vivência emocional intensa toda vez que eles são ativados. Por vezes, entretanto, essas estratégias não são saudáveis e funcionais, podendo gerar ainda mais sofrimento. Esses mecanismos são divididos em três e denominam-se processos esquemáticos, sendo eles dos tipos de manutenção, evitação e compensação (Young e outros, 2003/2008). A manutenção esquemática acontece quando: "o indivíduo percebe equivocadamente as situações, de maneira tal que o esquema é reforçado, acentuando a informação que o confirma ou negando a informação que o contradiz" (Young e outros, 2003/2008, p. 42). Ocorre, também, em nível comportamental, através de padrões de situações ou escolhas de relacionamentos que perpetuam seus esquemas. A evitação esquemática se trata do processo de perpetuação dos EIDs, por meio de evitação de informações, situações ou pessoas que contrariem as crenças do esquema. A compensação esquemática é uma tentativa de contrabalançar os EIDs, gerando cognições e comportamentos opostos ao que se esperaria com base no esquema em tela. Embora o indivíduo consiga camuflar seus EIDs, ao mesmo tempo torna-se cada vez mais incapaz de reconhecer sua vulnerabilidade caso ocorra falha no esquema.

Cabe refletir sobre como tais processos psicodinâmicos acontecem no âmbito clínico. Para Young e outros (2003/2008): "A relação terapeuta-paciente serve como antídoto parcial aos esquemas do paciente, e ele internaliza o terapeuta como 'adulto saudável', que luta contra os esquemas e busca uma vida emocionalmente satisfatória" (p. 56). Com efeito, a relação terapêutica é um elemento útil para compreender as duas fases da terapia do esquema, a saber: etapa avaliativa e etapa de mudanças.

É característica da etapa avaliativa: identificar os EIDs do paciente e realizar uma psicoeducação a respeito delas; estabelecer uma relação entre EIDs, história de vida e dificuldades atuais; incentivar a pessoa entrar em contato com suas emoções ligadas aos EIDs; identificar as estratégias de enfrentamento disfuncionais. Nesta etapa, é comum o uso de instrumentos de avaliação (questionários e inventários), bem como imagens mentais. A etapa de mudança, por seu turno, envolve outros dois conceitos principais da terapia do esquema (Young e outros, 2003/2008): a postura da reparentalização limitada e a técnica de confrontação empática. Ambos têm como objetivo a modificação das estruturas disfuncionais identificadas na etapa de avaliação. 
A reparentalização limitada ocorre dentro de limites terapêuticos estabelecidos, e é entendida como uma tentativa de o terapeuta servir com um anteparo relacional para o paciente preencher as suas necessidades emocionais não atendidas. Isso serve para que o terapeuta capte informações sobre o paciente de modo a considerar e a enfatizar tais necessidades, de modo que o paciente possa reconhecê-las como suas e aceitá-las (Young e outros, 2003/2008).

A confrontação empática, por sua vez, pretende possibilitar que o paciente supere suas resistências durante a terapia, sobretudo, quando ele não responder racionalmente ao que está acontecendo consigo e ao terapeuta. Assim, o psicólogo se coloca de modo mais confrontativo de modo a tentar mudar esquemas mais rígidos do outro (Young e outros, 2003/2008).

É importante que o terapeuta esteja atento e saiba identificar e intervir frente à ativação de um esquema de um paciente que apresente uma resistência emocional intensa. A própria relação terapêutica, portanto, é discutida entre os envolvidos nela, com o objetivo de explorar as possíveis estratégias saudáveis de enfrentamento do problema.

\section{Interlocuções entre as terapias centrada no cliente e do esquema}

Apontam-se, em seguida, algumas possíveis comparações entre a terapia centrada no cliente e a terapia do esquema, com o propósito de estabelecer aproximações e distanciamentos entre elas.

A terapia centrada no cliente é caracterizada como uma psicoterapia da reestruturação da personalidade, sem, no entanto, distinguir sua aplicação para certos tipos de cliente, em termos diagnósticos (Rogers, 1957/2008; Rogers \& Kinget, 1962/1977). Trata-se, pois, de uma clínica do reajustamento psicológico sem ser baseada em psicopatologias clássicas, em que a mudança da personalidade e do comportamento do cliente deve partir, sobretudo, do exame de seu self (Rogers, 1951/1992), não importando o tipo de pessoa que se submeta a psicoterapia. A terapia do esquema, por sua vez, também busca uma reestruturação da personalidade, porém, ao contrário da terapia centrada no cliente, restringe-se ao tratamento de pacientes diagnosticados, especificamente, com transtornos da personalidade, recorrendo a uma perspectiva psicopatológica clássica (DSM-V e CID-10).

As duas terapias em tela direcionam suas atenções aos processos do próprio terapeuta entendendo que eles afetam a dinâmica clínica com o cliente. $\mathrm{Na}$ terapia centrada no cliente, tais operacionalizações são compreendidas pelas 
condições postuladas como congruência, consideração positiva incondicional e compreensão empática (Rogers, 1957/2008). Na terapia do esquema, os estilos de enfrentamento e os esquemas do terapeuta podem afetar a forma com que a terapia se desenvolve. Conflitos entre esquemas podem ocorrer, uma vez que o terapeuta não tenha consciência de seus próprios processos, fazendo com que a relação terapêutica corra riscos, como (Young e outros, 2003/2008): os esquemas de ambos coincidirem, podendo levar a uma superidentificação do terapeuta para com o paciente; e ativação de comportamentos evitativos do terapeuta, através de intensas emoções do paciente.

O processo de compreensão empática na terapia centrada no cliente não necessariamente objetiva uma mudança cognitiva e comportamental do cliente, dado que o objetivo primário é a mudança da personalidade que organiza e expressa essas dimensões no ambiente. Logo, a reorganização da personalidade envolve mudanças de percepções, pensamentos e posturas. Na terapia do esquema a postura de confrontação empática está relacionada ao objetivo de satisfação das necessidades emocionais básicas, através de mudanças nos esquemas. O conceito de compreensão empática, elaborado por Rogers (1957/2008), destaca-se como um dos seus principais aspectos clínicos, dado que a percepção e a comunicação do quadro de referência interno do cliente possibilitam ao terapeuta acessar suas experiências, simbolizações e o campo fenomenológico, de acordo com os significados que emergem disso. Na terapia do esquema, a postura de confrontação empática ocorre quando o terapeuta adota uma postura de equilíbrio ideal entre a compreensão do esquema do cliente e a testagem de sua realidade, ao demonstrar como os esquemas que lhe geram sofrimento estão relacionados ao seu histórico de vida. A empatia foca, em específico, a forma como o cliente se comporta no início do desenvolvimento que Ihe foi adaptativo ou desadaptativo e Ihe requer mudanças (Young e outros, 2003/2008).

Em termos do uso e não uso da diretividade e da não-diretividade, as duas perspectivas não parecem excluir nenhuma das duas possibilidades, apesar de poderem dispor de frequências diferentes de atitudes. Rogers e Kinget (1962/1977) citam, através de exemplos de exercícios, categorias de possíveis respostas dadas pelo terapeuta, a saber, estimativa, interpretativa, tranquilizadora, exploradora e compreensiva. As estimativas, interpretativas, exploradoras e tranquilizadoras, poderiam ser entendidas como diretivas do terapeuta em relação ao cliente, pois se focam em indicações do que o cliente poderia ou deveria fazer, representar ou direcionar a sua consciência. Considerando que na terapia centrada no cliente um dos objetivos clínicos é 
envolver o terapeuta na experiência imediata do cliente. Por isso, os mencionados autores concluem que a resposta compreensiva é a mais próxima da postura acolhedora dessa abordagem pela reiteração, o reflexo do sentimento e a elucidação. Logo, a compreensão é o tipo de intervenção que expressa a nãodiretividade clínica, no sentido de o terapeuta partir da experiência e do self do cliente para estabelecer os seus entendimentos e suas intervenções clínicas.

$\mathrm{Na}$ terapia do esquema, o que poderia ser aludido como uma diretividade seria o processo de avaliação dos esquemas iniciais desadaptativos (EIDs), através do uso de instrumentos de avaliação, como questionários e inventários. Contudo, as análises das respostas devem ser complementares, juntamente ao olhar qualitativo na identificação dos EIDs. Outro aspecto diretivo encontra-se, comumente, na técnica de reparentalização limitada em momentos de confrontação empática (Young e outros, 2003/2008). Ressalta-se que Rogers (1959/1977), também, usou de instrumentos e medidas para avaliar a eficiência de sua proposta psicoterapêutica, porém com finalidades de pesquisa e não como recursos suplementares à intervenção clínica. Se, por um lado, a diretividade da terapia do esquema pode ser observada no uso de instrumentos avaliativos e momentos de confrontação empática; por outro, a identificação dos EIDs e estratégias de enfrentamento por meio da história de vida do paciente revela certo caráter não-diretivo, ao utilizar uma postura de observação aberta ao que emerge da experiência do outro. Entretanto, cabe contrapor esta postura não-diretiva com o fortalecimento do modo "adulto saudável" do paciente frente aos seus modos disfuncionais, um dos propósitos bem definidos desta terapia. Exercícios de imagens mentais, também, podem ser incluídos entre a diretividade/não-diretividade (Young e outros, 2003/2008).

Salienta-se que por se tratarem de terapias que pensam a constituição da personalidade, é possível notar uma semelhança teórica entre as noções rogeriana de campo fenomenológico e youngiana de esquema. Ambas aludem a uma composição de impressões de mundo e constituição de si-mesmo que serão elementos estruturantes da personalidade.

As duas perspectivas de terapia utilizam, pois, o construto de self em suas teorias, porém devido às suas diferentes influências, o entendem de forma distinta. Na terapia do esquema se utilizam de três dimensões que influenciam diretamente o self e seus EIDs (Young, 1999/2003): o temperamento, ao qual é geneticamente herdado; as experiências sistemáticas com figuras de afeto na infância; e o nível de gratificação de suas necessidades emocionais básicas. Na terapia centrada no cliente é nítida uma perspectiva mais dialógica, que destaca o campo fenomenológico na construção do self, ou seja, o mundo particular em 
que o indivíduo experimenta e que lhes geram impressões e percepções sobre si mesmo (Rogers, 1951/1992). O self funciona como uma função autorreguladora do próprio organismo, tendo o terapeuta o papel de acompanhar e facilitar o processo de contato com esse referencial interno e expressão dele na relação. Ainda assim, Rogers (1951/1992) não exclui o papel das origens biológicas nas necessidades de afeto, apesar dos limites nas pesquisas de sua época.

Por entenderem de formas distintas o construto de self, as abordagens analisadas têm diferentes maneiras de explicar os processos em que ocorrem as defesas da personalidade frente às suas tensões. Para Rogers (1951/1992), existe uma intencionalidade organísmica que funciona como processo regulador de diminuição das tensões. Nota-se isto pela noção de ajustamento e desajustamento, onde ocorre a simbolização ou a negação das experiências que condizem ou não com o self. Ou ainda no conceito de subcepção, em que se deforma/distorce as simbolizações de experiências ameaçadoras (Rogers, 1959/1977). Na terapia do esquema, os processos dos esquemas funcionam a partir das emoções, cognições e comportamentos, reforçando-os de forma a perpetuá-los. Dessa forma, a manutenção esquemática altera as percepções da realidade, supervalorizando e/ou distorcendo informações para que fique condizente com seu esquema, ou seja, trata-se de um mecanismo de defesa (Young, 1999/2003).

Rogers e Young partem dos afetos/emoções para sustentar suas intervenções e entendimento dos processos que constituem a personalidade, ainda que seus fenômenos sejam compreendidos de formas distintas. Rogers (1951/1992) afirma que "A emoção acompanha e, em geral, facilita o comportamento dirigido para uma meta" (p. 560), assim a facilitação desempenhada pelo terapeuta depende de um olhar para a experiência do cliente, fazendo com que a expressão das emoções aconteça livremente na relação e mudanças na percepção aconteçam. Na terapia do esquema, Young (1999/2003) utiliza de pesquisas acerca do sistema cerebral relacionado ao condicionamento do medo e trauma para demonstrar que as emoções e sensações corporais estão no cerne dos EIDs. Portanto, principalmente na fase de mudanças, a ativação dos esquemas exerce um papel crucial para que os EIDs sejam modificados através de métodos que vão além dos cognitivos. Assim, o terapeuta facilita o paciente na tomada de consciência da relação entre seus esquemas com as emoções ativadas, sensações corporais e possíveis memórias traumáticas. Este processo é fomentado intensamente por técnicas vivenciais, com a utilização de imagens mentais (Young e outros, 2003/2008). A distinção nas explicações do fenômeno se reflete na finalidade mais explícita da terapia do 
esquema, comparada a terapia centrada no cliente, que é o enfraquecimento dos EIDs e o fortalecimento de esquemas adaptativos.

Por fim, a ressignificação das experiências vividas perpassa as finalidades de ambas as perspectivas clínicas, apesar de apresentarem modos diferentes de obtê-la. Na terapia centrada no cliente, quando o cliente é capaz de funcionar de modo mais pleno, no sentido de ser capaz de apreciar e examinar tudo o que decorre de sua experiência e está ou não consoante ao seu self, ocorrem (re)significações mais satisfatórias (Rogers, 1959/1977). Na terapia do esquema, as ressignificações efetivas são alcançadas quando há modificações nos estilos de enfrentamento considerados desadaptativos (Young e outros, 2003/2008).

\section{Considerações finais}

Este estudo realizou um diálogo entre a terapia centrada no cliente e a terapia do esquema. Descrevemos os elementos teóricos e terapêuticos centrais que embasam tais propostas. Os pontos de interlocução encontrados foram: o uso/não uso do diagnóstico no tratamento da personalidade; atenção aos processos do terapeuta como influentes na dinâmica terapêutica; a questão da sustentação empática em termos de compreensão e confrontação; a diretividade/não-diretividade na postura terapêutica; semelhança entre os conceitos de campo fenomenológico e esquema; os entendimentos de self; os modos de defesa do self; a importância dos afetos/emoções nas intervenções clínicas; e as formas de alcançar a ressignificação terapêutica.

Salienta-se que a terapia centrada no cliente constitui uma rica fonte de pesquisas sobre o seu legado teórico, prático e de pesquisa clínica. Muitas correntes de psicoterapia ulteriormente desenvolvidas por psicólogos estadunidenses dentro do discurso acadêmico e científico recorreram a essa herança rogeriana. Embora tenhamos nos restringido à terapia do esquema, é possível observar elementos de diálogos possíveis com a análise funcional do comportamento, que trabalha com um desenho de pesquisa quase-experimental semelhante ao organizado por Rogers e faz releituras de algumas condições terapêuticas postuladas por ele. Nesse sentido, chamamos a atenção para o público brasileiro em relação a esse campo de reflexão, dado que tais correntes se valem de proposições lançadas por Rogers. Obviamente, não se tratam de continuidades, mas se aventa um campo de estudos que merece ser aprofundado e esclarecido para os humanistas que desatentam para isso, em prol de uma restrição ao que Rogers fez após se aposentar da clínica e da vida universitária nos anos de 1960 a 1980, e psicólogos cognitivos e 
comportamentais que não reconhecem, ou ignoram, o que Rogers deixou disponível.

Considerando a falta de material de natureza comparativa da terapia rogeriana com as abordagens cognitivas comportamentais, este estudo deve ser entendido como embrionário. Assim, o trabalho ora findado trata de um exercício inicial e pondera que outros pontos de interlocução podem ser elencados se analisados outros elementos teóricos e práticos presentes nas carreiras de Rogers e Young, como a questão da readaptação ou reajustamento da personalidade, ou se examinados seus elementos epistemológicos comuns, como a Psicologia da Gestalt e as psicanálises pós-freudianas, por exemplo.

\section{Referências}

Boainain, E. (1998). Tornar-se transpessoal: transcendência e espiritualidade na obra de Carl Rogers. São Paulo: Summus.

Campos, R. (2017). Carl Rogers com Michel Foucault (caminhos cruzados). Curitiba: Appris.

Castelo Branco, P. C. \& Cirino, S. D. (2016a). Reflexões sobre a consciência na fenomenologia e na abordagem centrada na pessoa. Gerais: Revista Interinstitucional de Psicologia, 9(2), 241-258. Recuperado em 4 de fevereiro, 2020 , de http://pepsic.bvsalud.org/pdf/gerais/v9n2/v9n2a07.pdf

Castelo Branco, P. C. \& Cirino, S. D. (2016b). Funcionalismo e pragmatismo na teoria de Carl Rogers: apontamentos históricos. Revista da Abordagem Gestáltica, 22(1), 12-20. Recuperado em 4 de fevereiro, 2020, de http://pepsic.bvsalud.org/pdf/rag/v22n1/v22n1a03.pdf

Castelo Branco, P. C., Monteiro, P. S. \& Felix, L. M. (2016). Diálogo entre os métodos educacionais de Paulo Freire e Carl Rogers. Perspectivas em Psicologia, 20(2), 110-126. Recuperado em 4 de fevereiro, 2020, de http://www.seer.ufu.br/index.php/perspectivasempsicologia/article/view/3 7218/19666

Crapanzano, V. (1991). Diálogo. Anuário Antropológico, 13(1), 59-80. Recuperado em 18 de maio, 2020, de https://dialnet.unirioja.es/servlet/articulo?codigo $=7396649$

Falcone, E. M. O. \& Ventura, P. R. (2008). Entrevista com Dr. Jeffrey Young. Revista Brasileira de Terapias Cognitivas, 4(1), 01-07. Recuperado em 4 de 
http://pepsic.bvsalud.org/pdf/rbtc/v4n1/v4n1a10.pdf DOI: 10.5935/18085687.20080010

Farber, B., Brink, D. \& Raskin, N. (2001). La psicoterapia de Carl Rogers: casos y comentarios. Bilbao: Editorial Desclée de Brouwer.

Gobbi, S. (2002). Teoria do caos e a abordagem centrada na pessoa. São Paulo: Vetor.

Gusmão, S. (2011). Comparando Freud e Rogers. João Pessoa: EDUFPB.

Holanda, A. (1998). Diálogo e psicoterapia: correlações entre Carl Rogers e Martin Buber. São Paulo: Lemos.

Kirschenbaum, H. \& Henderson, V. (1990). Carl Rogers: Dialogues. London: Constable.

Lima, T. \& Mioto, R. (2007). Procedimentos metodológicos na construção do conhecimento científico: a pesquisa bibliográfica. Revista Katálysis, 10(esp.), 37-45. Recuperado em 16 de fevereiro, 2021, de https://www.scielo.br/pdf/rk/v10nspe/a0410spe.pdf. doi: 10.1590/S141449802007000300004

Milhollan, F. \& Forisha, B. E. (1978). Skinner x Rogers: maneiras contrastantes de encarar a educação (A. Arruda, Trad.). São Paulo: Summus. (Original publicado em 1972).

Moreira, V. (2007). De Carl Rogers a Merleau-Ponty: a pessoa mundana na psicoterapia. São Paulo: Annablume.

Moreira, V. (2010). Convergências e divergências entre as psicoterapias de Carl Rogers e Frederick Perls. Revista do NUFEN, 2(1), 20-50. Recuperado em 4 de fevereiro, 2020, de http://pepsic.bvsalud.org/pdf/rnufen/v2n1/a03.pdf

Nye, R. D. (2005). Três psicologias: ideias de Freud, Skinner e Rogers (E. Moreira, Trad.). São Paulo: Pioneira Thomson Learning. (Original publicado em 1981).

Paludo, S. D. S. \& Koller, S. H. (2007). Psicologia Positiva: uma nova abordagem para antigas questões. Paidéia (Ribeirão Preto), 17(36), 09-20. Recuperado em 4 de fevereiro, 2020, de https://www.scielo.br/pdf/paideia/v17n36/v17n36a02.pdf. doi: $10.1590 /$ S0103-863X2007000100002

Pinheiro, F. P. H. A. \& Vieira, E. M. (2011). Convergências entre a abordagem centrada na pessoa e Sören Kierkegaard. Psicologia Argumento, 29(65), 
167-177. Recuperado em 4 de fevereiro, 2020, de https://periodicos.pucpr.br/index.php/psicologiaargumento/article/view/20 $\underline{143 / 19429}$

Ponte, C. R. (2010). Sobre os conceitos de indivíduo em Sören Kierkegaard e de pessoa em Carl Rogers: semelhanças e diferenças. Dissertação de Mestrado, Programa de Pós-Graduação em Psicologia, Universidade Federal do Ceará, Fortaleza, CE.

Rafaeli, E., Bernstein, D. \& Young, J. (2011). Schema therapy: distinctive features. New York: Taylor \& Francis Group.

Rogers, C. (1977). Teoria e pesquisa. Em Rogers, C. \& Kinget, M. Psicoterapia e relações humanas: teoria e prática da terapia não-diretiva. (Vol. 1., pp 25282, M. Bizotto, Trad.). Belo Horizonte: Interlivros. (Original publicado em 1959).

Rogers, C. (1992). Terapia centrada no cliente (C. Bartalonni, Trad.). São Paulo: Martins Fontes. (Original publicado em 1951).

Rogers, C. (2008). As condições necessárias e suficientes para mudança terapêutica na personalidade. Em J. Wood. (Org.). Abordagem centrada na pessoa (pp. 143-161, J. Wood, Trad.). Vitória: EDUFES. (Original publicado em 1957).

Rogers, C. \& Kinget, M. (1977). Psicoterapia e relações humanas: teoria e prática da terapia não-diretiva. (Vol. 2., 2 ed, M. Bizotto, Trad.). Belo Horizonte: Interlivros. (Original publicado em 1962).

Scorsolini-Comin, F. (2014). Aconselhamento psicológico com casais: interlocuções entre Psicologia Positiva e abordagem centrada na pessoa. Contextos Clínicos, 7(2), 192-206. Recuperado em 4 de fevereiro, 2020, de http://pepsic.bvsalud.org/pdf/cclin/v7n2/v7n2a08.pdf. doi: 10.4013/ctc. 2014.72 .07

Young, J. E. (2003). Terapia cognitiva para transtornos da personalidade: uma abordagem focada em esquemas (M. Veronese, Trad.). Porto Alegre: Artmed. (Original publicado em 1999).

Young, J. E., Klosko, J. S. \& Weishaar, M. E. (2008). Terapia do esquema: guia de técnicas cognitivo-comportamentais inovadoras (R. Costa, Trad.). Porto Alegre: Artmed. (Original publicado em 2003). 


\section{Nota sobre os autores:}

Marcel Gomes Oliveira é Graduado em Psicologia pela Universidade Federal da Bahia - Campus Anísio Teixeira. E-mail: marcelgomespsi@gmail.com.

Paulo Coelho Castelo Branco é Doutor em Psicologia pela Universidade Federal de Minas Gerais. Docente do Departamento de Psicologia da Universidade Federal do Ceará e do Programa de Mestrado em Psicologia da Saúde da Universidade Federal da Bahia - Campus Anísio Teixeira. E-mail: pauoccbranco@gmail.com.

Data de submissão: 29.05.2020

Data de aceite: 09.03.2021 